\title{
Workplace Stress Induced among Nurses at Mbarara Regional Referral Hospital, South West Uganda
}

TOR Salome Shiden ${ }^{1^{*}}$, Ndie Elkenah Chubike ${ }^{2}$ and Ofuti William ${ }^{2}$

${ }^{1}$ FCT Primary Health Care Board, Abuja Nigeria

${ }^{2}$ Department of Nursing Science, Ebonyi State University, Abakaliki, Nigeria

${ }^{3}$ Department of Nursing, Kampala International University, Isiaka Bushenyi Campus, South Western Uganda

*Corresponding author: Shiden TOR, FCT Primary Health Board, Abuja Nigeria, Tel: 251468814986; E-mail: chubike05@yahoo.com

Received date: August 01, 2017; Accepted date: August 24, 2017; Published date: September 02, 2017

Copyright: (c) 2017 Shiden TOR, et al. This is an open-access article distributed under the terms of the Creative Commons Attribution License, which permits unrestricted use, distribution, and reproduction in any medium, provided the original author and source are credited

\begin{abstract}
This study aimed at assessing the factors contributing to stress in nurses' workplace was conducted at Mbarara Regional Referral Hospital, South West Uganda. Random sampling method was used to select 50 nurses out of 180 that were on duty when data was collected. The data was collected using self-structured questionnaire. The results show that $25(50 \%)$, said that their job condition is stressful, $5(5 \%)$ said fair, $10 \%$ said they have a very poor job condition. $40 \%$ agreed that job promotion is done on merit, $20 \%$ of the respondents noted that promotion is done based on performance. $20 \%$ agreed that it's done depending on experience while $8 \%$ said it's done basing on vacancies and $12 \%$ were other factors. It was concluded that the working condition at Mbarara Referral Hospital present many stressor to nursing staff which include irregular working hours ,poor remuneration, poor communication and co-ordination by the administration. It was recommended that the hospital administration should regularize the working hours, improve on the salary of workers and also improve the communication channels with the nurses.
\end{abstract}

Keywords: Workplace; Stress induced; Nurses; Stressors

\section{Introduction}

The experience of stress represents a psychological state. It can result from exposure or threat of exposure to workplace psycho-social hazards. Therefore experience of stress is one important outcome of exposure to uncomfortable condition that threaten the individual's wellbeing in the work place. These uncomfortable working situations which are associated with the experience of stress are often termed stressors [1]. Workplace stress is the harmful and emotional response that can happen when there is a conflict between job demands on the employee and the amount of control an employee has over meeting these demands. Stress itself is a fact of nature every human being has to experience and react to. Stress can even be a positive experience that keep workers at alert, motivated and avoid dangers in day to day activities but on the other hand, it is commonly a negative experience causing poor performance at work and even at home. While some people have high expectations and sensitivity to the outcome of their work, others have low expectations and sensitivity to the outcome of their work and therefore will respond differently to the outcome of stress thus people have different stress experiences. HSE defined workplace stress as the adverse reaction people have due to excessive pressure or other types of demand on them at work.

Work stress among nursing staff has been a problem for years, as explained by Gelsema. Work stress can have a negative effect on mental and physical health. It can also adversely affect job satisfaction. Nursing is a professional job of looking after people who are seeking for healthcare and they include well persons, the sick, injured, very old and mentally retarded. This is a job that is dynamic (full of energy, ideas, continuously changing) at the same time it is unique because of the human life that is involved and every human being is unique. The causes of stress in nursing are tied to the role of nursing and the environment in which nurses' work [2]. The role of nursing is associated with multiple and conflicting demands imposed by nurse supervisors and managers, and by medical and administrative staff. Such a situation appears to lead to work overload and possible to role conflict. One form of such conflict often mentioned in surveys of nurses relates to the conflict inherent in the instrumental and goaloriented demands of "getting the patient better" and those related to providing emotional support and relieving patient stress. Research studies and current literature have indicated numerous factors affecting the stress and burnout of nursing staff working in long-term care. Factors include lack of knowledge in providing care for this population [3,4], conditions of work, including staffing, heavy workload; and taking care of clients with disabilities, agitation, or dementia [3].

The International Council of Nursing outlined the following as causes of work related stress in nursing: Working conditions like shift and week-end work, inadequate remuneration, hours of work, conflict, discrimination and danger in the work environment. Relationships at work inform of quality of relationships with peers, subordinates or supervisors. Role conflict and ambiguity like ill-defined role, functions, expectations and duties. Organisation structure and climate in form of communication policy and practice, major changes in the workplace, culture of the organisation, and lack of participation in decisionmaking. Work-home interface like competing demands on time and expectations. Career Development in form of underutilization of skills or failing to reach full potential, change to a position that do not suit the skills and interests of the individual, uncertain job expectations, job insecurity and lack of opportunities to learn and advance and Nature of the job like amount of physical and emotional stamina required, workload and work pace 
Page 2 of 4

It's important to recognise the causes of work related stress so that the appropriate mitigations can be put in place so as to address the problem and prevent its effect on the performance of nurses and keep them in the profession. It is for this reason that the researchers were compelled to carry out the research to find out factors causing stress so that they can possibly be addressed and thus create a stress reduced working environment in the hospital and the nursing profession as a whole. The Broad objective of the study is to identify factors that cause work related stress and how it affects the quality of health care among nurses in Mbarara Regional Referral Hospital, Western Uganda. The findings will help health administrators to identify what nurses undergo with regard to work related stress. It will help the authorities to understand the common cause of stress in the nursing department of Mbarara Regional Referral Hospital. The result obtained can be used to equip nurses with knowledge and attitude towards stress and its management.

\section{Research Method}

In this study a cross-sectional survey was used and this design was chosen because it was especially appropriate for describing the status of the phenomena and was appropriate for investigating the determinants and outcomes of causes of stress among nurses in Mbarara Regional Referral Hospital.

The study was conducted in Mbarara Regional Referral Hospital (MRRH) in Mbarara district. MRRH is located in the South Western Part of Uganda, in Mbarara Municipality and it is one kilometer from Mbarara town centre. Mbarara is $266 \mathrm{~km}$ from Kampala, it's the largest urban center in western Uganda, and it lies west of Masaka on the road to Kabale near Lake Mburo national park.

The study population of the research were all nurses working at Mbarara Regional Referral Hospital. The study focuses on all nurses irrespective of their educational status or religious beliefs. A simple random sampling technique was employed.

Total sample of 50 subjects were selected from 180 Nurses on duty during the time data were collected and who were willing to take part in the study. A systematic sampling was done and each study subject numbered from one onwards. Self-constructed questionnaire was used. Before data collection, a split half method was used to test the reliability of the instrument after a pilot study. A reliability test was carried out using chronbach alpha with a result of $0.8(80 \%)$ which proved that is reliability.

The study was carried out after the approval of the proposal by the ethics committee of Kampala International University. Letter of introduction from the School of Nursing sciences was obtained before the study. An informed consent was obtained from all subjects. Data collected from the study was analyzed by using the Statistical Package for Social Scientists (SPSS) version 16 and the results presented in form of tables and figures.

\section{Results}

\section{Socio demographic characteristics (Table 1)}

\begin{tabular}{|l|l|l|}
\hline & Frequency & Percentage \\
\hline Single & 30 & 61.5 \\
\hline Married & 10 & 19 \\
\hline
\end{tabular}

\begin{tabular}{|l|l|l|}
\hline Divorced & 3 & 6 \\
\hline Separated & 7 & 14 \\
\hline Total & 50 & 100 \\
\hline
\end{tabular}

Table 1: Marital status of the individuals.

Most of the respondents were single accounting for $61 \%$. The respondents who were married accounted for 10 (19.3). Those divorced were only 3 while those separated were only 7 (Table 2 ).

\begin{tabular}{|l|l|l|}
\hline Occupation & Frequency & Percentage\% \\
\hline BNS nurses & 9 & 18.0 \\
\hline Registered nurses & 6 & 12.0 \\
\hline Comprehensive nurses & 11 & 22.0 \\
\hline Enrolled nurses & 17 & 34.0 \\
\hline Nursing aid & 4 & 9.0 \\
\hline Others & 3 & 5.0 \\
\hline Total & 50 & 100 \\
\hline
\end{tabular}

Table 2: Area of specialty.

The majority of the respondents interviewed were enrolled nurses (34\%) followed by comprehensive nurses with $22 \%$. BNS nurses constituted $18 \%$ and nursing aid were only $9 \%$ (Figure 1 ).

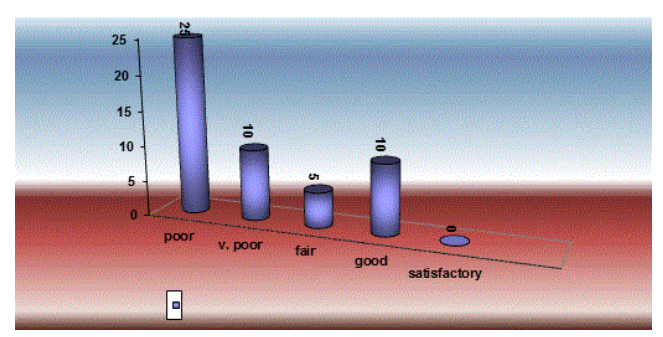

Figure 1: Assessment of present job condition.

Majority of the respondents 25 (50\%), said that their job condition is stressful, $5(5 \%)$ said fair, $10 \%$ said they have a very poor job condition. On the other hand only $5 \%$ said the present job condition is fair while another $5 \%$ said it's good (Figure 2).

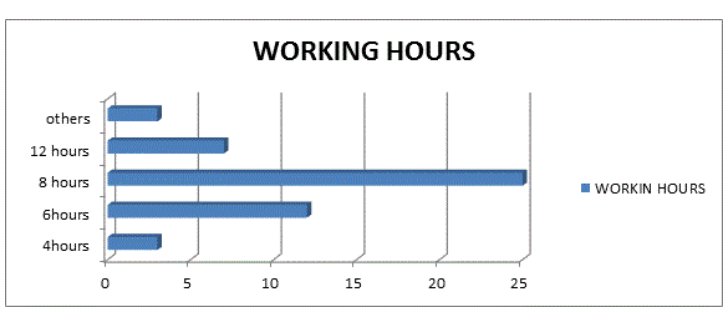

Figure 2: Assessment of working hours on the present job. 
Page 3 of 4

Most of the respondents $25 \%$ said that they work eight hours in a day, 12 of them agreed that they only work $6 \mathrm{~h}$ a day, 3 said they work $4 \mathrm{~h}$ (Table 3).

\begin{tabular}{|l|l|l|}
\hline Stressors & Frequency & Percentage\% \\
\hline Uncooperative workmates & 12 & 13.3 \\
\hline High patient to nurse ratio & 13 & 14.8 \\
\hline Inadequate materials & 15 & 17.7 \\
\hline Poor remuneration & 12 & 12.6 \\
\hline Longer working hours & 18 & 19.4 \\
\hline Exposure to professional hazards & 10 & 11 \\
\hline Poor appraisal technique & 9 & 10 \\
\hline All the above & 2 & 2.2 \\
\hline Total & 91 & $100 \%$ \\
\hline
\end{tabular}

Table 3: Respondent's opinion on what they consider stressors in the work place.

Most of the respondents $19.4 \%$ complained of long working hours, $13.3 \%$ said that they get stresses because of uncooperative workmates, $14.8 \%$ said there is high patient to nurse ratio while $12.6 \%$ said it's due to poor remuneration. Exposure to professional hazards was noted by $11.0 \%$ of the respondents (Figure 3 ).

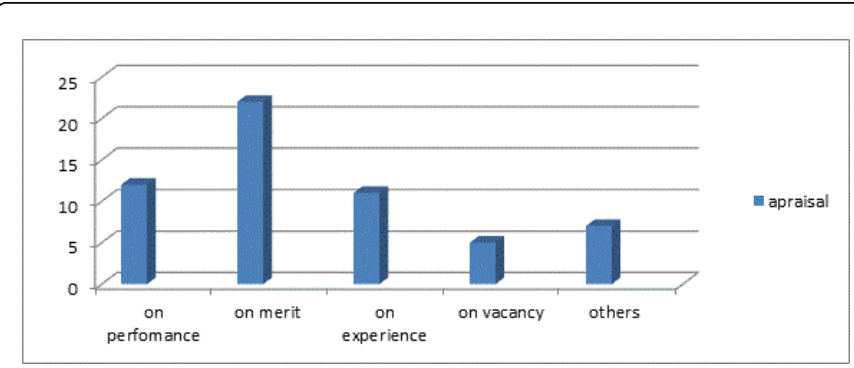

Figure 3: Response towards job appraisals.

Most of the respondents (40\%), agreed that job promotion is done on merit, $20 \%$ of the respondents noted that promotion is done based on performance. $20 \%$ agreed that it's done depending on experience while $8 \%$ said it's done basing on vacancies and $12 \%$ were other factors (Table 4).

\begin{tabular}{|l|l|l|}
\hline Number of times & Frequency & Percentage \\
\hline Once a year & 8 & 16 \\
\hline Quarterly & 12 & 24 \\
\hline Monthly & 30 & 60 \\
\hline Others & 0 & 0 \\
\hline total & 50 & 100 \\
\hline
\end{tabular}

Table 4: The number of times department undertake continuous professional development.
Most of the respondents (60\%), especially the nursing aids said that they receive monthly professional development, 12 of the respondents said that the professional development is quarterly while $16 \%$ said that it is once a year (Table 5).

\begin{tabular}{|l|l|l|}
\hline Chain of communication & Frequency & Percentage \\
\hline Regular and satisfactory & 11 & 22 \\
\hline Regular but unsatisfactory & 8 & 16 \\
\hline Not regular and unsatisfactory & 31 & 62 \\
\hline Does not exist & 0 & 0 \\
\hline total & 50 & 100 \\
\hline
\end{tabular}

Table 5: Assessing the chain of communication.

On the assessment of chain of communication in vertical and horizontal level among nurses, $64 \%$ of the nurses said communication on both levels is not regular and is unsatisfactory, 22\% agreed its regular and satisfactory, $16 \%$ said it's regular but unsatisfactory while none said it does not exist.

\section{Discussion}

This chapter gives a vivid description of the above analyzed data and stipulated recommendations as per the study findings, all the (100\%) respondents submitted their questionnaires fully filled except for some ambiguous answers which needed more explanation.

Most of the respondents were single accounting for $61 \%$. The respondents who were married accounted for 10 (19.3). Those divorced were only 3 while those separated were only 7 this clearly indicated that most of the respondents are not yet ready to get married and settle down to have families. The majority of the respondents interviewed were enrolled nurses (34\%) followed by comprehensive nurses with $22 \%$. BNS nurses constituted $18 \%$ and nursing aid were only $9 \%$.

$100 \%$ of the respondents had not only ever heard of stress but also experienced a stressful situation.

Majority of the respondents 25 (50\%), said that their job condition was stressful, $5(5 \%)$ said fair, $10 \%$ said they have a very poor job condition. On the other hand only $5 \%$ said the present job condition is good. This data indicates more than half $(60 \%)$ of the respondents were not happy with their job conditions as per the time of this research while only $40 \%$ are found in either fair or good. In a nursing profession where the patient's health is the main goal, it is important to ensure the well-being of the nurses so that they work effectively and with the zest in which they were trained otherwise as sick (stressed) nurse cannot in anyway restore the wellness of his or her own patients. This confirmed ICN observation that working conditions in hospitals lead to stress among nurses.

When asked the about the working hours, most of the respondents $25 \%$ said that they work $8 \mathrm{~h}$ in a day, 12 of them agreed that they only work $6 \mathrm{~h}$ a day, 3 said they work 4 hours. The nurse in-charge explained that the working hours vary because of the programs in the duty roster, for example those who work at night may work longer hours but get four free days after each one week, on the other hand, the senior nurses are given shorter working hours than other nurses. 
When the respondents were asked about their main stressors, there was mixed reactions in that $19.4 \%$ complained of long working hours, $13.3 \%$ said that they get stressed because of uncooperative workmates, $14.8 \%$ said there is high patient to nurse ratio while $12.6 \%$ said its due to poor remuneration. Exposure to professional hazards was noted by $11.0 \%$ of the respondents. This indicates that the main stressing factor in nursing profession at Mbarara Hospital is longer working hours. This problem is always due to lack of trained personnel (manpower) and high nurse to patient ratio. Poor cooperation of the workmates was also the second most stressing issue in the study area and this may be due to lack of coordination at vertical and horizontal level and poor communication between the concerned departments. This is in line with Ude et al. [5] who stated that nurse do not consistently use their subordinate in goal setting and this leads to stress among nurses in their place of work.

Job appraisal is an important tool in an organization because it rewards achievers and keep the workers on toes, therefore it was also specifically noted that most of the respondents (44\%) agreed that job promotion is done on merit, $24 \%$ of the respondents noted that promotion is done based on performance. $22 \%$ agreed that it's done depending on experience while $14 \%$ said it's done basing on other factors. This indicated that there is little or no biasness in promoting or appraising a nurse in the study area. From the above analysis $44 \%$ (22) accepted that they have ever been promoted only once, $22 \%$ agreed they have been promoted once since they started, $20 \%$ said they have been promoted three times since they started working but $12 \%$ (6) have never been promoted since they started working. When relating the working experience of the respondents to the number of times they have ever been promoted, it was discovered that most of the respondents with longer working experience had the highest number of promotions.

On issues of remuneration, the respondents were asked to compare the wages they receive as per the services rendered, $30 \%$ of the respondents said it's not satisfactory, another $30 \%$ said it's fair while only $16 \%$ commented that it is very good and $24 \%$ said it is good. This indicates that the respondents were not contented with the salaries they get especially nurses of low cadres. Of the 12 respondents who said they are comfortable with the remuneration $90 \%$ were the senior nurses. The researcher discovered that most respondents were not comfortable in answering this question because of fear of being victimized but after being assured of confidentiality, they reluctantly answered the question. These findings agree with Sherries who stated that poor remuneration leads to stress among nurses. Morquis and Huston [6] also stated that salary is the major part of motivation that enhance attitude to work.

To ensure continued education progress, (60\%) especially the nursing aids said that they receive monthly professional development,
12 of the respondents said that the professional development is quarterly while $16 \%$ said that it is once a year. The nursing aids are the beneficiaries in this training program because they learn on the job. This is contrary to Ndie et al. [7] recommended that trained nurses should be exposed to continue professional development to enable the impact positively on their subordinates.

Proper coordination and communication among workers is the cornerstone for good service delivery, therefore the respondents were asked to grade their relationship with administrators, most of the respondents (30\%) said that their relationship with the administrators is fair, $24 \%$ said its poor, $16 \%$ said they relate with administrators in a good way while $18 \%$ (9) graded the relationship as very poor. On the same note, the majority $(70 \%)$ said it affects their working environment, $20 \%$ said that it does not affect while $10 \%$ (5) of the respondents were not sure if it affects or not.

\section{Conclusion}

It was concluded that the working condition at Mbarara Referral Hospital present many stressor to nursing staff which include irregular working hours, poor remuneration, poor communication and coordination by the administration.

\section{Recommendations}

It was recommended that the hospital administration should regularize the working hours, improve on the salary of workers and also improve the communication channels with the nurses.

\section{References}

1. Seaward BL (2006) Managing stress: Principles and strategies for health and wellbeing. Jones Bartlett.

2. European Agency for Safety and Health at Work (2000) Research on Work Related Stress.

3. Cohen-Mansfield J, Noelker LS (2000) Nursing staff satisfaction in longterm care: An overview In: Cohen-Mansfield J, Ejaz FK, Werner P (eds.,) Satisfaction in long-term care, New York.

4. Kennedy B, Covington K, Evans T, Williams CA (2000) Mental health consultation in a nursing home. Clinical Nurse Specialist 14: 261-266.

5. Ude CC, Nwaneri AC, Ezenduka PO, Ndie EC (2016) Evaluation of nursing perception of use of management by objectives as motivator by ward nurse Manager at Enugu State University Hospital, Parklane, Enugu. Weber Medicine and Clinical Case Report 2: 1-4.

6. Marquis BL, Huston CJ (2000) Leadership role and management function in nursing: Theory and practice. Lippincoth, New York, pp: 280-298.

7. Ndie EC, Ezenduka PO, Ehiemere I, Mba CJ (2016) Effect of professional designation on the level of task performance by community health workers in Enugu State. J Health Sci 4: 155-159. 